\title{
Correspondence
}

Irish Journal of Psychological Medicine, 39 (2022).

doi:10.1017/ipm.2019.30

\section{Autism spectrum disorder and Irish prisoners}

The global prevalence of autism spectrum disorder (ASD) is 62/10 000 (Elsabbagh et al. 2012). A large cross-sectional study of schoolchildren (Sweeney et al. 2016) estimated the prevalence of ASD as $1 \%$ in Irish mainstream schools.

The prevalence of ASD internationally in correctional settings is higher than community estimates. One study in a US maximum security setting (Fazio et al. 2012) suggests a prevalence of $4.4 \%$. A more recent systematic review found that the prevalence of ASD in 'forensic populations' varies from $2 \%$ to $18 \%$ (Rutten et al. 2017).

Dein \& Woodbury-Smith (2010) report that individuals with ASD, including Asperger's syndrome, who offend represent a small but significant group. People with ASD are overrepresented within the criminal justice system worldwide and failure to detect ASD among offenders is not uncommon (Mouridsen, 2012). However, the relationship between ASD and offending has been debated (Gunasekaran \& Chaplin, 2012). Murphy (2010) notes that in the case of ASD, regardless of the offence committed, there is rarely a single responsible factor, with most explanations being framed in terms of the associated cognitive, sensory and social naivety difficulties and that dealing with sensory overload or hypersensitivity is relevant.

Little is known about prevalence rates, prisoner experiences and treatment needs of those with ASD in Irish prisons.

We sought to systematically review published evidence relating to ASD in Irish prisoners between January 1966 and July 2017 by searches of electronic bibliographic databases using the pre-determined inclusion criteria: (a) presented data on the prevalence of, treatment needs or experiences of those with ASD, (b) sampled from detainees or sentenced prisoners, (c) the ASD was diagnosed based on a validated research instrument and/or a clinical examination and (d) presented quantitative or qualitative findings. No relevant studies were identified.

We suggest that the lack of relevant studies is not explained by a lack of ASD among the Irish prison population of 3700 prisoners (Irish Penal Reform Trust, 2017). Previous research has outlined that Irish prisoners have higher rates of mental illness as compared to the general population (Kennedy et al. 2004) and potentially higher rates of intellectual disabilities (IDs) as compared to international estimates (Murphy et al. 2000; Gulati et al. 2018a). ASD is a significant comorbidity in people with ID and $70 \%$ of those with ASD will have a comorbid ID. Even if the prevalence of ASD is the same as the community (1\%), there should be c.37 individuals with ASD in Irish prisons.

The varied presentations of ASD and the inherent difficulties in researching such a heterogeneous group may account, in part, for a lack of studies. It is further possible that many cases of ASD do not come to the attention of the criminal justice system or psychiatric in-reach services; there may not be a prior formal diagnosis, those dealing with such prisoners may not have the training to recognise ASD and there may be a lack of effective screening tools or a lack of resources to refer suspected cases to. ASD advocacy may therefore have a specific role in this sub-population. Potentially small absolute numbers and limitations to available expertise may explain the lack of studies evaluating quantitative (prevalence) data and qualitative data relating to the experiences of prisoners with ASD.

The core impairments in ASD can have a significant bearing on an individual's journey through the criminal justice system, including the police interview, fitness to be tried, culpability (Kristiansson \& Sorman, 2008) and the appropriateness of custodial disposal (O'Sullivan, 2017). Kristiansson \& Sorman (2008) cite the need for more research into the area of criminal responsibility in those with ASD while recognising the complexity of such a task in a disorder where the severity of neuropsychiatric deficits and psychosocial dysfunction is broad.

Difficulties in pragmatic or social communication, literalness, overcompliance and a tendency towards acquiescence together with difficulties with eye contact and frankness may put ASD sufferers at a disadvantage both in terms of their limited ability to engage with legal processes and assumptions on the part of law enforcement regarding apparent guilt and remorse.

Prisons are complex social environments with strong hierarchies where vulnerable prisoners are open to intimidation, emotional, physical or sexual abuse and exploitation. Robertson \& McGillivray (2015) comment on the difficulties faced by incarceration in those with ASD where issues with social communication, understimulation or overstimulation and difficulties adapting to change lead to problems including maladaptive coping behaviours, interpersonal conflict and adverse forensic outcomes. The ability of those with ASD to meaningfully engage with rehabilitate, 
adaptive living programmes or group-based cognitive behavioral therapy may be limited. They may also be more vulnerable to institutionalisation and require specific interventions to prepare them for a return to community living.

In conclusion, this area warrants further academic attention in Ireland in order to inform practice and policy in dealing with this vulnerable population. Research would be welcomed on the prevalence rates of ASD in Irish prisons. Screening tools such as the Ritvo Autism and Asperger Diagnostic Scale Screening Tool RAADS-14 (Eriksson et al. 2013) may be a useful starting point to screen for undiagnosed ASD. This could be followed by a comparative study on the experience of those with ASD in the Irish prison system compared to a matched non-ASD group. Such qualitative research would help to inform a debate on policy, education, dispositional arrangements, alternative rehabilitation options as well as on the shape of specialised forensic services or additional in-reach services. It would also assist clarification of the differences between 'prevalence' and 'unmet need' which are separate issues. A study of prevalence and needs in elderly prisoners (Davoren et al. 2014) found the range of unmet needs on a spectrum of 'none' to 'substantive'.

Awareness training around ASD for police, court representatives and prison officers could help in ensuring fair treatment within the criminal justice system. Pilot programmes aimed at improving awareness among police have reported positive outcomes (Murphy et al., 2018). Developments in screening and care pathways for those with ID in Irish prisons (Gulati et al., 2018a, 2018b) may help improve diagnosis rates for those with ID who have comorbid ASD.

The aim of additional focus on research and training would be to ensure that the civil, legal and human rights of those with ASD in Irish prisons are respected.

\section{Conflicts of Interest}

NM has no conflicts of interest to disclose. GG is Chair of the Faculty of Forensic Psychiatry at the College of Psychiatrists of Ireland and the views expressed are his own.

\section{References}

Dein K, Woodbury-Smith M (2010). Asperger syndrome and criminal behaviour. Advances in Psychiatric Treatment 16, 37-43.

Davoren M, Fitzpatrick M, Caddow F, Caddow M, O'Neill C, O'Neill H, Kennedy HG (2014). Older men and older women remand prisoners: mental illness, physical illness, offending patterns and needs. International Psychogeriatrics 27, $1-9$.
Elsabbagh M, Divan G, Koh YJ, Kim YS, Kauchali S, Marcín C,Montiel-Nava C, Patel V, Paula CS, Wang C, Yasamy MT, Fombonne E (2012). Global prevalence of autism and other pervasive developmental disorders. Autism Research: Official Journal of the International Society for Autism Research 5, 160-179.

Eriksson JM, Andersen LM, Bejerot S (2013). RAADS-14 Screen: validity of a screening tool for autism spectrum disorder in an adult psychiatric population. Molecular Autism 4, 49.

Fazio R, Pietz CA, Denney R (2012). An estimate of the prevalence of autism-spectrum disorders in an incarcerated population. Open Access Journal of Forensic Psychology 4, 69-80.

Gunasekaran S, Chaplin E (2012). Autism spectrum disorders and offending. Advances in Mental Health and Intellectual Disabilities 6, 308-313.

Gulati G, Murphy V, Clarke AM, DelCelliher K, Meagher D, Dunne CP (2018a). Intellectual disability in Irish prisoners; systematic review of prevalence. International Journal of Prisoner Health 14, 188-196.

Gulati G, Quigley S, Murphy V, Yacoub E, Bogue J, Kearns A, O'Neill C, Kelly M, Morrison A, Griffin G, Blewitt M, Fistein E, Meagher D, Dunne CP (2018b). A novel care pathway for prisoners with intellectual disability designed through a Delphi process. International Journal of Prisoner Health 14, 276-286.

Irish Penal Reform Trust (2017). Facts and figures. http:/ / www.iprt.ie/prison-facts-2. Accessed 14 November 2018.

Kennedy HG, Monks S, Curtin K, Wright B, Linehan S, Duffy D, Teljeur C, Kelly A (2004). Mental Illness in Irish Prisoners. National Forensic Mental Health Service: Dublin (http:/ / www.tara.tcd.ie/handle/2262/63924). Accessed 1 June 2019.

Kristiansson M, Sorman K (2008). Autism spectrum disorders: legal and forensic psychiatric aspects and reflections. Clinical Neuropsychiatry 5, 55-61.

Mouridsen SE (2012). Current status of research on autism spectrum disorders and offending. Research in Autism Spectrum Disorders 6, 79-86.

Murphy D (2010). Understanding offenders with autismspectrum disorders: what can forensic services do? Advances in Psychiatric Treatment 16, 44-46.

Murphy M, Harrold M, Carey S, Mulrooney M (2000). A Survey of the Level of Learning Disability among the Prison Population in Ireland. Retrieved from (http:/ / www.iprt.ie/files/learning_disability_report.pdf). Accessed 14 November 2018.

Murphy V, Kelleher M, Gulati G (2018). Letter to the Editor. Irish Journal of Psychological Medicine 35, 345-346.

O'Sullivan O (2017). Autism spectrum disorder and criminal responsibility: historical perspectives, clinical challenges and broader considerations within the criminal justice system. Irish Journal of Psychological Medicine 35, 333-339.

Robertson CE, McGillivray JA (2015) Autism behind bars: a review of the research literature and discussion of key issues. The Journal of Forensic Psychiatry \& Psychology 26, 719-736. 
Rutten AX, Vermeiren R, Van Nieuwenhuizen C (2017).

Autism in adult and juvenile delinquents: a literature review. Child and Adolescent Psychiatry and Mental Health 11, 45.

Sweeney MR, Staines A, Boilson A (2016). Autism Counts. A Report on Autism Spectrum Disorder prevalence estimation in the Republic of Ireland. Dublin City University: Dublin. Available at: (http://www.alphagalileo.org/AssetViewer. aspx?AssetId=109368\&CultureCode $=$ en). Accessed 17 October 2018.
NOREEN MOLOnEY

Graduate Entry Medical School, University of Limerick, Plassey, Limerick, Ireland

\section{Gautam Gulati}

Graduate Entry Medical School, University of Limerick, Plassey, Limerick, Ireland

(Email: gautam.gulati@hse.ie) 